\title{
CIRCADIAN RHYTHMS AND FUNCTIONALITY: A COMPARISON BETWEEN OUTPATIENTS WITH DIAGNOSIS OF UNIPOLAR DEPRESSION VERSUS BIPOLAR DEPRESSION.
}

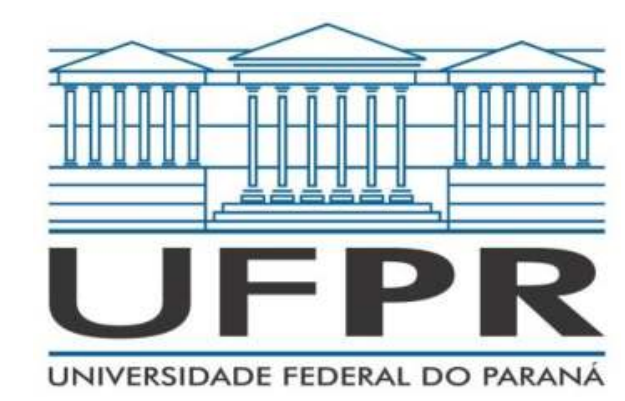

D. Zorzetto Filho ${ }^{1}$, A.T.D.P. Sampaio', L.S. Kanayama1.

1 Universidade Federal do Paraná, Departamento de Medicina Forense e Psiquiatria, Curitiba, Brazil.

\section{OBJECTIVES}

To compare circadian rhythm and functional abnormalities among patients with bipolar disorder (depressive episode) and patients with unipolar depression.

\section{BACKGROUND}

Previous studies have demonstrated the existence of the relationship between circadian rhythm and functional changes in individuals with mood disorders. The majority of these studies focused on bipolar disorder and few compared those changes between patients in the depressive episode of bipolar disorder and those diagnosed with unipolar disorder in one and the same study.

\section{MATERIALS AND METHODS}

The research sample consisted of 60 participants, composed of 30 individuals with bipolar depression and 30 individuals with unipolar depression from an outpatient Mental Health Clinic at Hospital de Clínicas - Federal University of Paraná. The circadian rhythm (BRIAN), functionality (FAST) and severity of the depressive episode were evaluated through 3 different scales, respectively BRIAN, FAST and HAM-D. Sociodemographic and clinical data were obtained from medical records.

\section{RESULTS AND CONCLUSION}

When comparing the FAST and BRIAN scores in both groups, the statistical results showed that there were no relationships between the diagnostic categories and the circadian rhythm abnormalities (Mann- Whitney, $p=0.299$ ) or the functionality (Mann-Whitney, $p=0.5442$ ). However, the severity of the depressive episode was correlated with changes in the circadian rhythm (Kruskal-Wallys, $p<0.001$ ) and that duration of disease correlated with impairment of functionality (Spearman, $p$ $<0.0019)$.

The negative repercussions in the patients' daily life do not depend so much on the category of the diagnosed mood disorder, but on the severity of the depressive episodes, especially with regard to the circadian rhythm.

\begin{tabular}{|c|c|c|c|c|}
\hline Correlation & $\begin{array}{c}\text { Unipolar } \\
\text { Depression } \\
(n=30)\end{array}$ & $\begin{array}{c}\text { Bipolar } \\
\text { depression } \\
(n=30)\end{array}$ & $\begin{array}{c}\text { All } \\
\text { participants } \\
(n=60)\end{array}$ & Test \\
\hline HAM-D X BRIAN Total & $\begin{array}{l}p<0,001 \text { and } \\
\text { rho }=0,6020\end{array}$ & $\begin{array}{l}\mathrm{p}<0,001 \mathrm{e} \\
\mathrm{rho}=6071\end{array}$ & $\begin{array}{l}p<0,001 \text { and } \\
\text { rho }=0,6245\end{array}$ & $\begin{array}{l}\text { Spearman } \\
\text { correlation }\end{array}$ \\
\hline HAM-D X FAST Total & $\begin{array}{l}p<0,001 \text { and } \\
\text { rho }=0,5145\end{array}$ & $p=0,1247$ & $\begin{array}{l}p<0,001 \text { and } \\
\text { rho }=0,4030\end{array}$ & $\begin{array}{l}\text { Spearman } \\
\text { correlation }\end{array}$ \\
\hline Severity of the & & & & \\
\hline $\begin{array}{l}\text { Depressive Episode X } \\
\text { BRIAN Total } \\
\text { Severity of the }\end{array}$ & $p<0,001$ & $p<0,001$ & $p<0,001$ & Kruskal - Wallis \\
\hline $\begin{array}{l}\text { Depressive Episode X } \\
\text { FAST Total }\end{array}$ & $p<0,1062$ & $p=0,05717$ & $p=0,0116$ & Kruskal - Wallis \\
\hline
\end{tabular}

Comparison between total Hamilton scale values and other scales (FAST and BRIAN)

CHART 2: Diagnose X FAST Score

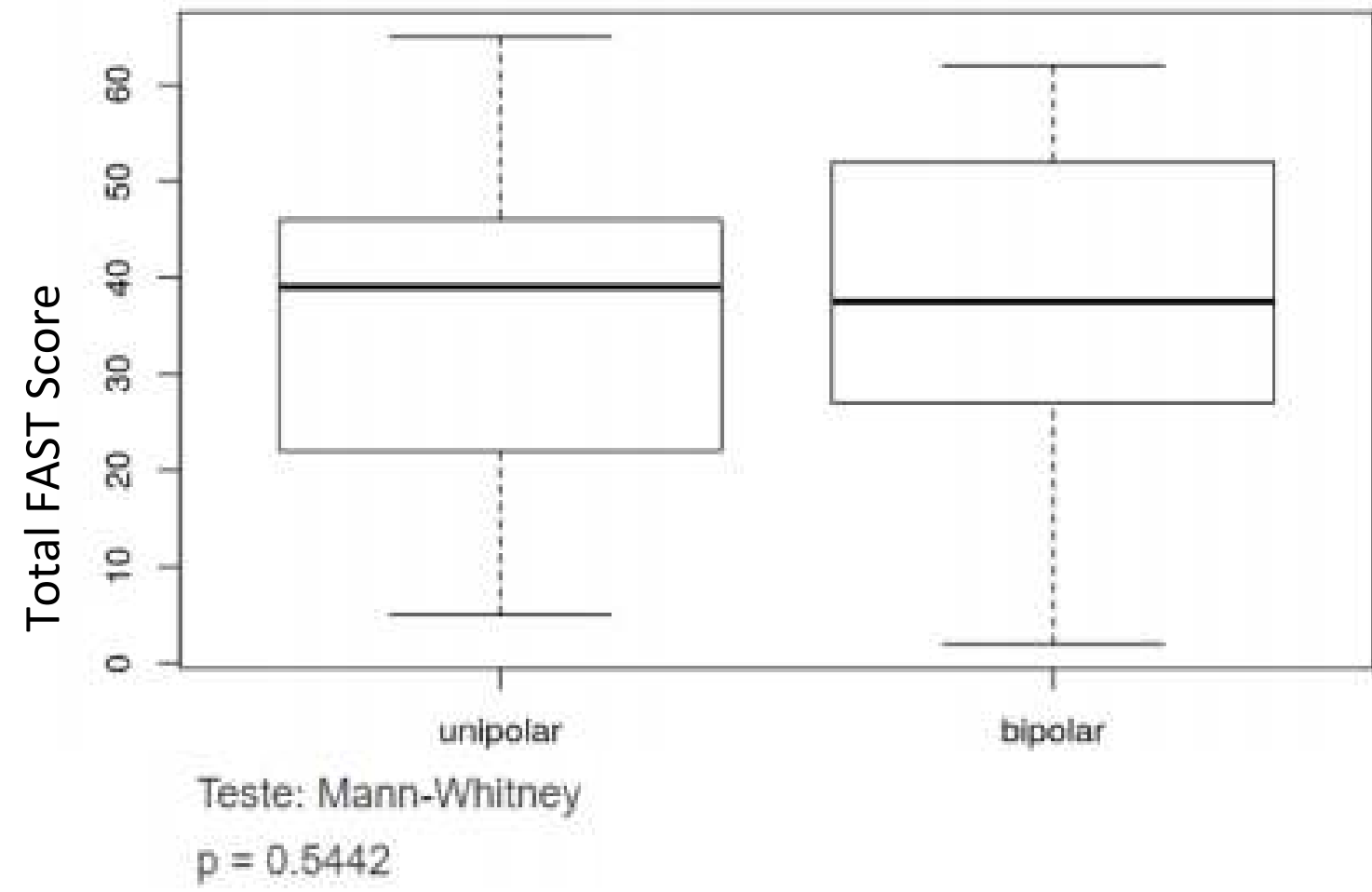

